\title{
Design and Implementation of Hybrid Solar Wind Energy Tower
}

\author{
S. Jensie Anita, Jewel Joy C, March. A S, Priyanka. B J
}

\begin{abstract}
The proposed method might be a possible key to the combination of high levels of radiation by solar energy and speed of the wind on a monthly average basis. Wind Energy Tower (WET) and Hybrid Solar (HS) is combined to form the HSWET system and the function of solar panel in parallel with wind turbines thereby acquiring a higher total of renewable energy values. It is essential to measure the output power and monitor it regularly. And also the design of $\mathrm{HSWET}$ was being paralleled with an prevailing solar hybrid system have made changes from a single solar panel to a tree like structure which includes for solar panel to get more output power than before and the results of the proposed Hybrid Solar and Wind Energy Tower system resulted in a greater efficiency.
\end{abstract}

Keywords: Hybrid Solar, Radiation, Solar panel, Wind Energy Tower

\section{INTRODUCTION}

In recent days, the population growth during the years from 1980 to 2015 has increased from 4.4 billion to 6 billion and constantly will be on the rise to upto a total of more than 7 billion by the end of 2016 is estimated by World Bank Group (WBG). This increase will take a toll growth in the demand coal is diminishing day by day and this limitation demands to look out for alternative fuels.

The growth in the field of renewable energy plays a major role as the alternative energy source. However, an only one type of renewable energy system is inadequate for achieving the energy demand in the highly populated areas due to the constraint space for huge plants to generate energy. For instance, a vast wind or a solar plant is highly not possible to system in an urban area. There is need for the advancement of the HSWET becomes mandatory. The project plan aims to take a city as the location for utilization and to study the behavior of solar radiation and wind speed [1].

And also the project was constrained on warranting an economically feasible solution by which the materials used for the HSWET. Further in this a lot of consideration was given in the usage of biodegradable constituents. In the end the efficiency needs to be maintained for both the HSWET with batteries are working at the same time by taking into contemplation the size of the electronic components involved.

Revised Manuscript Received on December 30, 2019.

S. Jensie Anita*, Assistant Professor, Department of Electrical \& Electronics Engineering, AarupadaiVeedu Institute of Technology , Chennai, India.

Jewel Joy C, March A S, Priyanka B J, UG Student, Department of Electrical \& Electronics Engineering, AarupadaiVeedu Institute of Technology, Chennai, India for the energy. The availability of natural fuel such as gas,

\section{PROPOSED HSWET CHARACTERISTICS}

The diagrammatic representation of the system which comprises of energy conversion basically combines the solar tracking system and wind conversion system to a charge controller which acts as a control unit. The process of converting the energy begins with 2 distinct renewable sources of energy that are the Wind Energy Conversion System (WECS) and Photovoltaic System (PVS) [2].

The HSWET is intended to be planned as the roof top application in residential areas as an alternate power source by employing the energy conversion to electric power. WECS employs a rotating mechanism which is driven by the wind. It helps to turn ON a DC motor attached on the device thereby convert the wind energy to $\mathrm{AC}$ voltage, and then it is converted into DC voltage through bridge rectifier [3].

Simultaneously, Photo-Voltaic (PV) system will generate DC voltage through the panels. The energy generated by the Hybrid Solar and Wind Energy Tower is equals to the sum of the WECS, PW and PVS, PPV. A controller is being employed to join the voltage to charge a $6 \mathrm{~V}$ battery. It is considered as the main source of power to the load [4].

\section{A. Design and Implementation IC7805}

Voltage Regulator (VR) is an IC7805 in fig. 1. and its voltage rating is $5 \mathrm{~V}$ that provides the output voltage to $5 \mathrm{~V}$ output for vary ranges of input voltage. VR is an excellent component preventing the circuit from the input voltage fluctuations, and provide additional protection precaution to the circuit. It is widely used device, economical and easily obtainable.

With the help of very few capacitors and IC7805 a reliable voltage regulator can be build in lesser time. Pin out of the VR provides with an additional provision to add the heat sink. Maximum input voltage of the VR is $35 \mathrm{~V}$. When the VR reaches its higher voltage until the threshold is $35 \mathrm{~V}$ is achieved. VR doesn't produce heat, when its voltage value nearer from $7.2 \mathrm{~V}$ to $12 \mathrm{~V}$ and doesn't required any heat sink.

Fig. 2. shows the circuit diagram of 7805 Voltage Regulator IC. IC has heated, when the high input voltage is applied to that, and the electricity is separated from IC 7805. So that heat sink is provision.

7805 regulate $5 \mathrm{~V}$ and 7806 regulate $6 \mathrm{~V}$ and so on. The schematic representation of IC7805 is given below fig.1and shows the using of IC7805, there are 3 pins in IC 7805, and pin 1 takes the input voltage and pin 3 produces the output voltage. The ground of both pin1, 3 are given to pin 2 . To avoid power losses, it is necessary to maintaining the input as $7.2 \mathrm{~V}$ to $9 \mathrm{~V}$. 
Fig. 3. Represent the Pin Diagram of 7805 Voltage Regulator IC

PV is the rooftop panel which is observed on domestic and industrial- electrical energy is produced from PV directly. The sun's energy is used to generate heat by solar thermal technologies, and from that heat energy is used to generate electricity. It doesn't require any rotating parts while converting light energy into electrical energy.

Because of light rays, electrons in the PV cell get separate from their host atoms. The photon (light energy) is being captured by these electrons. Electrons can be release from the host atom by photons which gives enough energy. One path casing called a PN-junction layer is near the upper surface of the panel.

A free electron crosses this $\mathrm{PN}$-junction it cannot return back easily, which produces a negative voltage upper layer of the panel and the positive voltage visible on the rear surface of the solar panel. To obtain power in terms of voltage and current from the panel by connecting the external circuit to the upper and rear surface of the solar cell. Group of solar cells form together modules and its life time is 20-40yr. usually PV modules are mounted on the roof of the house will generate electricity. Typically a single PV module generates the power about 200KWh (per square meter),

In addition, few other applications of PV systems consist of the following as powering of calculators and wrist watches, lighting. Large PV system able to produce electrical energy that is used to pump water, to supply electricity for a single home or business firm, to power communications equipment, or to form large arrays that supply electricity to thousands of consumers. Several advantages of PV systems are supply electricity where electricity distribution systems (power lines) are inactive, and they can also supply electricity to a power grid. The main advantage of this PV low cost, less maintenance, easy to install, required less space, and small in size, pollution free.

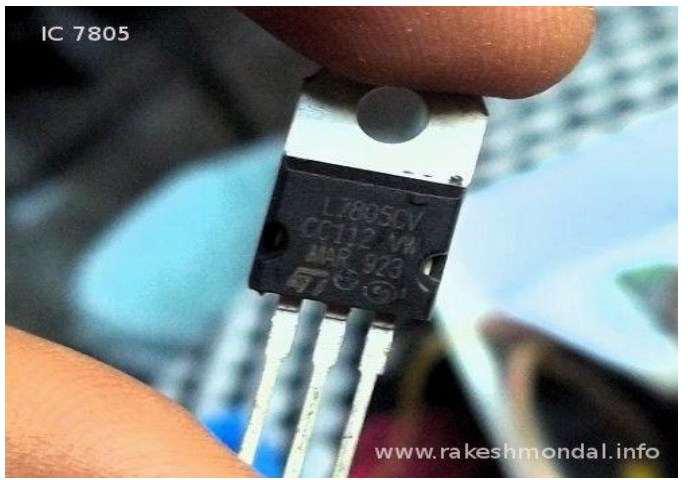

Fig. 1. 7805 Voltage Regulator IC

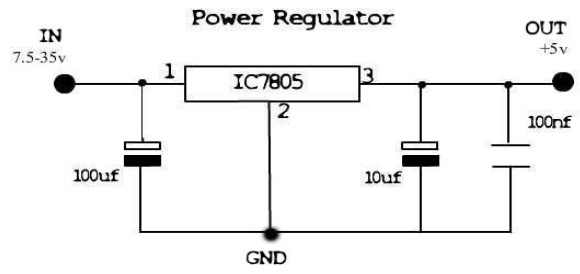

Fig. 2.Circuit diagram of 7805 Voltage Regulator IC.

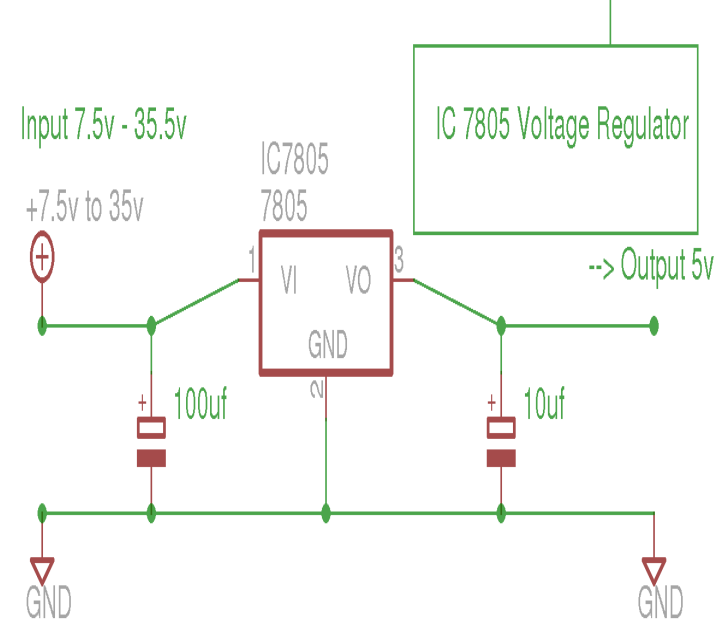

Fig. 3.Pin Diagram of 7805 Voltage Regulator IC.

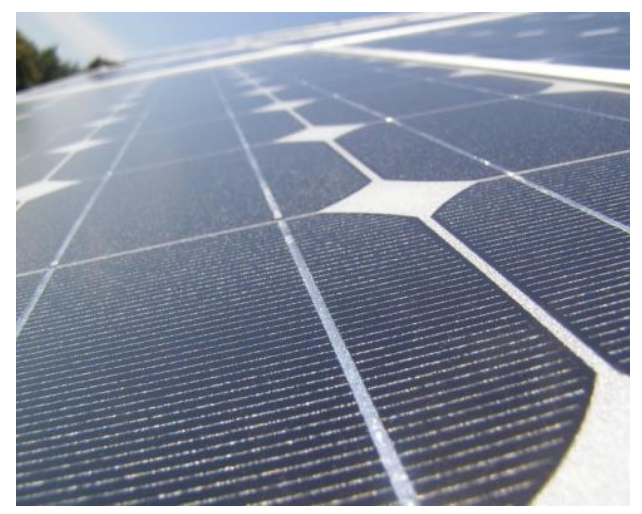

Fig. 4.Applications of Photovoltaic Systems

III. SIMULATION OPOSED DIAGRAM OF HSWET

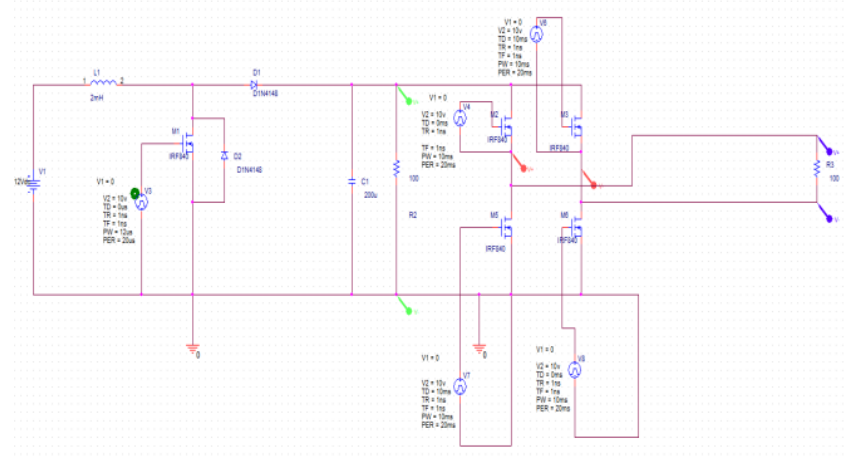

Fig. 5.Simulation Circuit of HSWET in Closed Loop 


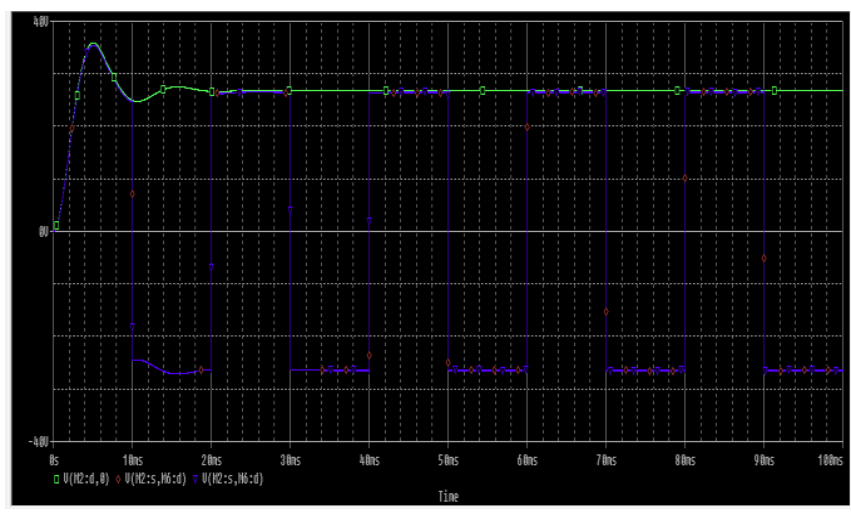

Fig. 6.Simulation Circuit for Output Obtained from the HSWET

Diagram of HSWET / Simulation circuit of HSWET in closed loop is represent in fig. 5. Simulation circuit for Output obtained from the HSWET is shown in fig. 6. Sealed Maintenance Free (SMF) Battery: it is designed to offer reliable and low maintenance power. For the application of solar and wind energy system, lighting application, telecommunication, and UPS applications. It is also called as Valve Regulated Lead Acid (VRLA-Battery) and it is available from the voltage range of $12 \mathrm{~V}$. This type of batteries is subjected into rural and power deficit areas, deep cycle applications. It is compulsory to send power instantly.

In recent technology, nobody can manage the requirement used for battery systems that are designed to improve essential capable information and to run the basic instrumentations for expected areas. Poor quality batteries can bring about the loss of information and equipment stoppages that can cost organizations significant economic losses. After that, the UPS sections are utilization for reliable and verified battery system. In last decade, lithium battery is act as portable power battery.

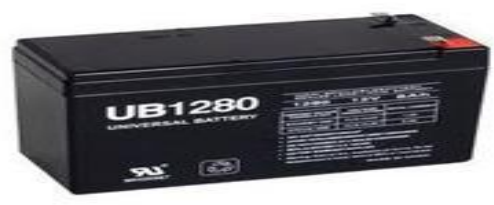

Fig. 7.SMF Battery

\section{RESULT AND DISCUSSION}

The proposed system was developed as a solution that falls under hybrid technology to catch the collective high range of solar radiation and high range of wind speed on a monthly basis. The HSWET simultaneously perform the functions of wind turbines and solar panel. The output power value obtained from the HSWET is maintained on daily basis. The designed HSWET system compared with an existing made changes from a single solar panel. The results of the proposed HSWET system show greater efficiency than existing.

\section{CONCLUSION}

In this paper, the prototype of HSWET system was successfully designed and it is creating by using wood and plastic are the natural equipment use at low cost. And the prototype of the system is performed perfectly and it is monitored by LabVIEW software. The HSWET is an improved version of a fixed PV power system is utilized in the domestic application in recent days.

Additionally, a review on the results that is obtained from the prototype reveals that the proposed method of this Hybrid Wind and Solar Energy Tower can be implemented in real life after a few scaling up measures on the basis of requirements and its applications. Further, it has viable advantages to serve the society after being installed in suburban areas as an alternative energy conversion system that operates in dual mode.

\section{REFERENCES}

1. Penava, S. Galijasevic.,A. Muharemovic., and M. Penava, M. "Optimal design and demonstrative application of standalone hybrid renewable energy system". In 2014 IEEE International Energy Conference, 2014 pp. $960-967$

2. Maity, Tanmoy, Sushma Kakkar, and Rajesh Kumar Ahuja., Control of standalone Wind/PV hybrid renewable power generation, IEEE 7th Power India International Conference, 2016, pp. 1-5.

3. S.B.Mohod, V.R. Parihar, and S.D. Nimkar, Hybrid power system with integration of wind, battery and solar PV system. IEEE International Conference on Power, Control, Signals and Instrumentation Engineering, 2017, pp. 2332-2337.

4. T.R. Mtshali, G. Coppez, S. Chowdhury, and S. P. Chowdhury. "Simulation and modelling of PV-wind-battery hybrid power system", Power and Energy Society General Meeting, 2011, pp. 1-7.

5. V. B. Manimaran, "Design and Implementation of Solar-Wind Combo for Hybrid Energy Application," International Journal of MC Square Scientific Research, vol.5, No.1 Nov 2013.

6. S.Siva, "Automatic Solar Tracker "International Journal of MC Square Scientific Research, Vol.8, No.1 Nov 2016.

\section{AUTHORS PROFILE}

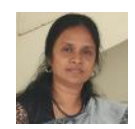

S.Jensie Anita, Assistant Professor, Department of Electrical \& Electronics Engineering, Aarupadai Veedu Institute of Technology, Chennai, India.

Jewel Joy, UG Student, Department of Electrical \& Electronics Engineering, Aarupadai Veedu Institute of Technology, Chennai, India.

March A S, UG Student, Department of Electrical \& Electronics Engineering, Aarupadai Veedu Institute of Technology, Chennai, India.

Priyanka B J, UG Student, Department of Electrical \& Electronics Engineering, Aarupadai Veedu Institute of Technology, Chennai, India. 